\title{
BMJ Open Nutrigenetics, omega-3 and plasma lipids/lipoproteins/apolipoproteins with evidence evaluation using the GRADE approach: a systematic review
}

\author{
Justine Keathley (10 , ${ }^{1,2}$ Véronique Garneau, ${ }^{1,2}$ Valérie Marcil, ${ }^{3,4}$ David M Mutch, ${ }^{5}$ \\ Julie Robitaille, ${ }^{1,2}$ Iwona Rudkowska, ${ }^{6,7}$ Gabriela Magdalena Sofian (D) ,8 \\ Sophie Desroches, ${ }^{1,2}$ Marie-Claude Vohl (D) ${ }^{1,2}$
}

To cite: Keathley J, Garneau V, Marcil V, et al. Nutrigenetics, omega-3 and plasma lipids/ lipoproteins/apolipoproteins with evidence evaluation using the GRADE approach: a systematic review. BMJ Open 2022;12:e054417. doi:10.1136/ bmjopen-2021-054417

- Prepublication history and additional supplemental material for this paper are available online. To view these files, please visit the journal online (http://dx.doi.org/10.1136/ bmjopen-2021-054417)

Received 16 June 2021 Accepted 28 January 2022

D) Check for updates

(c) Author(s) (or their employer(s)) 2022. Re-use permitted under CC BY-NC. No commercial re-use. See rights and permissions. Published by BMJ.

For numbered affiliations see end of article.

\section{Correspondence to}

Dr Marie-Claude Vohl;

marie-claude.vohl@fsaa.ulaval. ca

\section{ABSTRACT}

Objectives Despite the uptake of nutrigenetic testing through direct-to-consumer services and healthcare professionals, systematic reviews determining scientific validity are limited in this field. The objective of this review was to: retrieve, synthesise and assess the quality of evidence (confidence) for nutrigenetic approaches related to the effect of genetic variation on plasma lipid, lipoprotein and apolipoprotein responsiveness to omega-3 fatty acid intake.

Design A systematic review was conducted using three search engines (Embase, Web of Science and Medline) for articles published up until 1 August 2020. We aimed to systematically search, identify (select) and provide a narrative synthesis of all studies that assessed nutrigenetic associations/interactions for genetic variants (comparators) influencing the plasma lipid, lipoprotein and/or apolipoprotein response (outcomes) to omega-3 fatty acid intake (intervention/exposure) in humansboth paediatric and adult populations (population). We further aimed to assess the overall quality of evidence for specific priority nutrigenetic associations/interactions based on the following inclusion criteria: nutrigenetic associations/interactions reported for the same genetic variants (comparators) influencing the same plasma lipid, lipoprotein and/or apolipoprotein response (outcomes) to omega-3 fatty acid intake (intervention/exposure) in humans-both paediatric and adult populations (population) in at least two independent studies, irrespective of the findings. Risk of bias was assessed in individual studies. Evidence was evaluated using the Grading of Recommendations Assessment, Development and Evaluation (GRADE) approach with a modification to further consider biological plausibility.

Results Out of 1830 articles screened, 65 met the inclusion criteria for the narrative synthesis $(n=23$ observational, $n=42$ interventional); of these, 25 met the inclusion criteria for GRADE evidence evaluation. Overall, current evidence is insufficient for gene-diet associations related to omega-3 fatty acid intake on plasma apolipoproteins, total cholesterol, high-density lipoproteincholesterol, low-density lipoprotein (LDL)-cholesterol and LDL particle size. However, there is strong (GRADE rating: moderate quality) evidence to suggest that male $A P O E-E 4$ carriers (rs429358, rs7412) exhibit significant triglyceride
Strengths and limitations of this study

- Comprehensive systematic review guided by Preferred Reporting Items for Systematic Reviews and Meta-Analyses.

- Critical appraisal of the evidence guided by Grading of Recommendations Assessment, Development and Evaluation (GRADE) with a modification to further consider biological plausibility in addition to the standard components of the GRADE approach.

- Inability to conduct a meta-analysis given the comprehensive overview of studies and thus heterogeneity.

- Several included studies without replication; most evidence was low or very low quality according to GRADE.

reductions in response to omega-3-rich fish oil with a dose-response effect. Moreover, strong (GRADE rating: high quality) evidence suggests that a 31-SNP nutrigenetic risk score can predict plasma triglyceride responsiveness to omega-3-rich fish oil in adults with overweight/obesity from various ethnicities.

Conclusions Most evidence in this area is weak, but two specific nutrigenetic interactions exhibited strong evidence, with generalisability limited to specific populations.

PROSPERO registration number CRD42020185087.

\section{INTRODUCTION}

Cardiometabolic disease is a health concern worldwide. ${ }^{1}$ Nutrigenetic research demonstrates that there is significant inter-individual variability in cardiometabolic risk factor levels, in part based on a combination of genetic and nutrition-related risk factors. ${ }^{2} 3$ For example, protein intake has consistently been shown to influence measures of body weight and composition dependent on FTO genotype (rs9939609 or loci in strong linkage disequilibrium (LD)). ${ }^{45}$ Consumers indicate great interest in personalised nutrition based 
on genetics, ${ }^{6}{ }^{7}$ however, a lack of industry oversight ${ }^{89}$ has led to highly variable scientific validity of nutrigenetic tests available to consumers. While recognising that some groups question whether genetic testing for personalised nutrition is ready for 'prime time', Görman and colleagues suggested that there are certain specific nutrigenetic interactions with strong evidence that could be considered for implementation into clinical practice by expert committees who are responsible for creating dietary guidelines. ${ }^{10}$ With this in mind, systematic reviews that include an evaluation of levels of evidence are urgently needed in order to determine if there are any nutrigenetic associations that may warrant potential implementation into practice.

The dominant omega-3 polyunsaturated fatty acids are eicosapentaenoic acid (EPA) and docosahexaenoic acid (DHA), which typically come from marine sources (eg, fish oil), and alpha-linolenic acid (ALA), which are rich in plant sources (eg, canola oil) ${ }^{11}{ }^{12}$ It is well established that higher intakes of omega-3 fatty acids from foods or supplements (hereinafter referred to collectively as 'omega-3s'), particularly from long-chain EPA and DHA, tend to improve indicators of cardiometabolic health. ${ }^{12} 13$ In terms of their lipid and lipoprotein lowering effects, omega-3s have consistently demonstrated an impact on triglycerides (TG). ${ }^{14}$ High-quality evidence from population-based studies suggests that long-chain omega-3s (EPA and DHA) reduce plasma TG by about $15 \% .{ }^{14}$ There is also high-quality evidence suggesting that EPA and DHA can raise high-density lipoprotein (HDL) cholesterol. ${ }^{14}$ Other studies have further demonstrated a relationship between omega-3 and HDL-cholesterol, ${ }^{15}$ low-density lipoprotein (LDL)-cholesterol, ${ }^{15}$ total cholesterol, ${ }^{16-18}$ apolipoproteins ${ }^{19}$ and LDL particle size. ${ }^{20}$ Despite several studies with significant findings for these outcomes, when reviewing the evidence, studies have demonstrated conflicting results for the impact of omega-3 on many lipid profile outcomes. ${ }^{14}$ Genetic variation could explain this heterogeneity. EPA and DHA have been shown to significantly impact the expression of thousands of genes including those involved in inflammatory and atherogenic pathways. ${ }^{21} 22$ Evidence now demonstrates that the health impacts of omega-3 intake could differ based on genetic variation. ${ }^{23}{ }^{24}$ Despite the potential for omega-3s to have a significant positive impact on health outcomes, population intakes of omega-3s tend to be low. ${ }^{25}$ While the WHO's adequate intake level for adults is $200-250 \mathrm{mg} \mathrm{EPA}+\mathrm{DHA}$ per day, ${ }^{26}{ }^{27}$ the mean reported intake of EPA+DHA in the USA is only approximately $100 \mathrm{mg} /$ day. ${ }^{25}$ Nutrigenetic interventions have the potential to motivate improvements in dietary intake beyond population-based interventions. ${ }^{28}$ Additionally, evidence suggests that genetic variability affects health responses to omega-3s. ${ }^{23}$ Thus, critically appraising and grading the evidence for nutrigenetic interactions related to omega-3s and plasma lipids, lipoproteins and apolipoproteins is an important research priority. The most recent systematic review on nutrigenetic interactions related to omega-3s and intermediate phenotypes of cardiovascular disease was conducted nearly a decade ago, and this study did not evaluate the quality of evidence using an established methodology. ${ }^{29}$ Therefore, we aimed to provide a comprehensive summary of current evidence related to inter-individual variability in plasma lipid, lipoprotein and apolipoprotein responses to omega-3 intake (plant and marine sources) based on genetic variations. Overall, the specific objectives of this study were as follows:

- Objective 1. Systematically search, identify (select) and provide a narrative synthesis of all studies that assessed nutrigenetic associations/interactions for genetic variants (comparators; ie, outcomes in those with a specific genotype for a genetic variant compared to a different genotype) influencing the plasma lipid, lipoprotein and/or apolipoprotein response (outcomes) to omega-3 fatty acid intake (intervention/exposure) in humans-both paediatric and adult populations (population).

- Objective 2. Assess the overall quality of evidence for specific priority nutrigenetic associations/interactions based on the following inclusion criteria: nutrigenetic associations/interactions reported for the same genetic variants (comparators) influencing the same plasma lipid, lipoprotein and/or apolipoprotein response (outcomes) to omega-3 fatty acid intake (intervention/exposure) in humans-both paediatric and adult populations (population) in two independent studies, irrespective of the findings.

\section{METHODS}

Patient and public involvement

There was no direct patient involvement.

\section{Literature search}

The review process was guided by previously established methods, including a previously outlined five-step systematic review process. ${ }^{30} 31$ The search engines Embase, Web of Science and Medline OVID were used to conduct the search starting in May 2020 and screen for articles meeting inclusion criteria, using the comprehensive search terms outlined in online supplemental table 1, properly combined by Boolean operators. The literature was searched up until 1 August 2020 (there was no minimum start date; any article published prior to this date was included in the search). A Preferred Reporting Items for Systematic Reviews and Meta-Analyses (PRISMA) diagram (figure 1) guided the article screening process. $^{32}$

\section{Inclusion and exclusion criteria}

Original studies were included if they were written in English or French. Inclusion criteria were developed using the Population, Intervention, Comparison, Outcomes (PICO) and Population, Exposure, Comparison, Outcomes (PECO) methods $^{33}{ }^{34}$ for interventional and observational research, respectively. These are detailed in table 1 for each study objective. 


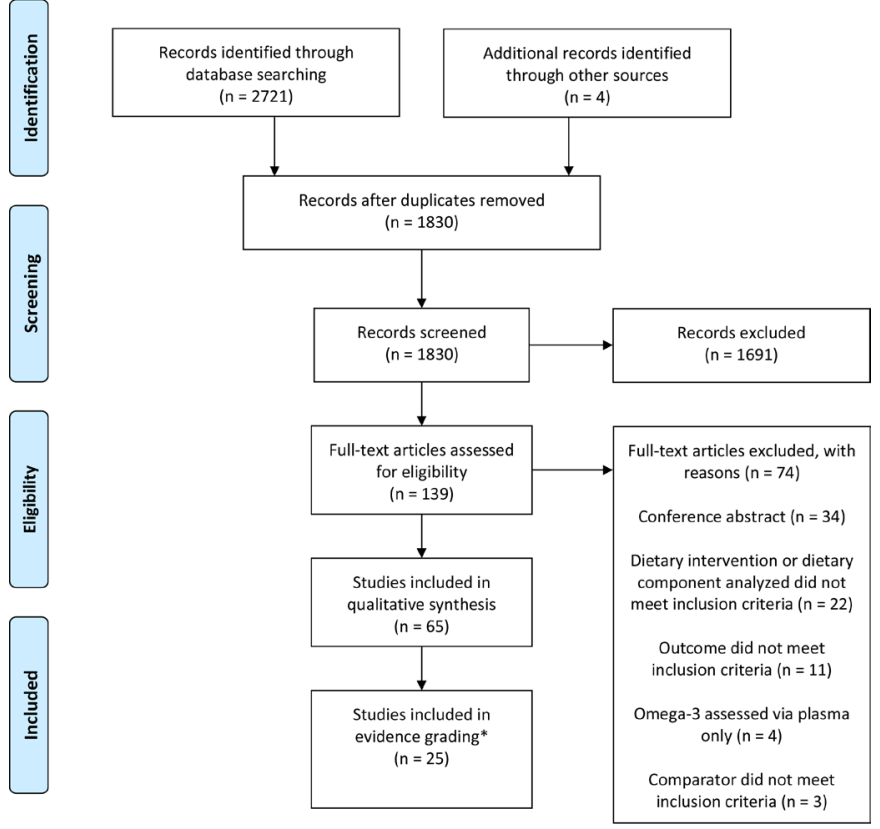

Figure 1 Preferred Reporting Items for Systematic Reviews and Meta-Analyses (PRISMA) flow diagram. *The original PRISMA flow diagram indicated the number of studies included in meta-analysis in this box. This has been revised for the purposes of this research.

\section{Table 1 PICO/PECO for study objectives}

\section{PICO/PECO for objective 1}

\begin{tabular}{ll}
\hline Population & $\begin{array}{l}\text { Human studies (adult and paediatric) } \\
\text { Intervention/Exposure }\end{array}$ \\
$\begin{array}{l}\text { Omega-3s (total omega-3 or various } \\
\text { types; supplemental and/or dietary } \\
\text { intake) }\end{array}$ \\
Comparison & Genetic variation \\
Outcomes & HDL-cholesterol, LDL-cholesterol, \\
LDL particle size, total cholesterol, \\
apolipoproteins and/or TG
\end{tabular}

\section{PICO/PECO for objective $2^{*}$}

$\begin{array}{ll}\text { Population } & \text { Human studies (adult and paediatric) } \\ \text { Intervention/Exposure } & \begin{array}{l}\text { Omega-3s (total omega-3 or various } \\ \text { types; supplemental and/or dietary } \\ \text { intake) }\end{array} \\ \text { Comparison } & \begin{array}{l}\text { Genetic variation in the same genetic } \\ \text { location (gene(s) and SNP(s)) }\end{array} \\ \text { Outcomes } & \begin{array}{l}\text { The same outcome of interest } \\ \text { among studies with the same genetic } \\ \text { comparators: HDL-cholesterol, LDL- } \\ \text { cholesterol, LDL particle size, total } \\ \text { cholesterol, apolipoproteins and/or } \\ \text { TG }\end{array}\end{array}$

*Nutrigenetic associations/interactions were included in objective 2 , in the evidence grading process, irrespective of the findings, provided that they had been reported in at least two independent studies on the same gene(s) and SNP(s), and the same plasma outcome.

HDL, high-density lipoprotein; LDL, low-density lipoprotein; SNPs, single nucleotide polymorphisms; TG, triglycerides.
There were no limitations to the population characteristics (all populations/patient samples were included). Animal studies were excluded. Dietary interventions and observational studies involving omega-3 fatty acid consumption (total omega-3 or various types; supplemental and/or dietary intake) and comparing lipid and/or lipoprotein and/or apolipoprotein outcomes between different genetic variations based on omega-3 dietary or supplemental intake (and not blood fatty acid levels; eg, EPA and DHA in red blood cells) were included in the narrative synthesis. In included studies, samples had to be stratified on the basis of genetic variation. Specific lipid and lipoprotein outcomes of interest were: HDL-cholesterol, LDL-cholesterol, LDL particle size, total cholesterol, apolipoproteins and TG. Studies that reported ratios of the aforementioned lipid parameters (eg, HDL-cholesterol to total cholesterol ratio) were also included. Both observational and interventional studies were included, as well as single-gene, polygenic and genome-wide association studies. Differences in study designs and methods were considered when developing the overall evidence grades, as further detailed later. Associations/interactions reported in two independent studies formed the basis of the inclusion criteria for objective 2, in which nutrigenetic associations/interactions were prioritised for evidence grading. This is further detailed in table 1 and in the Evidence grading section.

\section{Article selection and data extraction}

Two independent investigators (JK and VG) screened articles using the computer software Covidence (including title, abstract and full-text screening) and extracted data from the included articles. Reference lists of included articles and of a systematic review on a similar topic ${ }^{29}$ were also screened for relevant articles. Data extraction templates were piloted by two independent investigators (JK and VG) on ten included studies and revised accordingly. The final data extraction templates included the following components for each study: first author name and year, study design, genetic approach, population and sample size, study duration (interventional studies only), genes and single nucleotide polymorphisms (SNPs) analysed with rs numbers, quantity and type of omega-3, comparisons (eg, a control group or different amount/ type of omega-3s as well as genetic grouping), lipid/ lipoprotein/apolipoprotein outcome(s), whether or not the study reported that they followed the STrengthening the REporting of Genetic Association Studies (STREGA) guidelines and a summary of statistically significant study findings relevant to the research question. Corresponding authors of included studies were contacted as needed to provide clarity and/or additional information about the included studies.

\section{Evidence grading}

Upon reading all full-text articles included, and summarising the body of evidence (online supplemental file 1), SNPs/nutrigenetic risk scores (nutri-GRSs) and subsequent lipid/lipoprotein/apolipoprotein outcomes 
were systematically prioritised and selected for evidence grading, if a specific nutrigenetic association/interaction was reported in at least two independent studies. To clarify, this refers to the same SNP(s)/nutri-GRS (or SNPs in strong LD) being assessed and influencing the same lipid/lipoprotein outcome in at least two studies. For these nutrigenetic associations/interactions, we proceeded with evidence grading, while including all studies relevant to the particular nutrigenetic association/interaction, irrespective of the findings. Consistency of results was then one of several factors considered when grading the body of evidence. The Grading of Recommendations Assessment, Development and Evaluation (GRADE) approach indicates that a single study rarely (if ever) results in strong evidence, but two studies (typically randomised controlled trials (RCTs)) can indicate strong evidence if they are graded highly using the GRADE criteria. ${ }^{35}$ Prior to selecting the nutrigenetic associations/ interactions (genetic variants and lipid/lipoprotein/ apolipoprotein outcomes) for evidence grading, LD was assessed using the SNIPA SNP Annotator Software ${ }^{36}$ for genes located on the same chromosome and arm (determined using the Online Mendelian Inheritance in Man database) as outlined in the summary of results' tables in the column labelled 'Cytogenic location of gene(s)' (online supplemental file 1). Strong LD was defined as $r^{2}>0.8$ and location $<250 \mathrm{~kb}$ away from the index SNP location. SNPs in strong LD were considered together for the purposes of evidence grading.

Based on our abovementioned predetermined criteria for specific nutrigenetic topic selection for evidence grading, nutrigenetic associations/interactions that were not included in the evidence grading process likely have weak evidence (at minimum due to lack of replication, eg, ZNT8 rs13266634 and HDL-c or TG responsiveness to omega-3, which has only been assessed in a single study ${ }^{37}$ ). According to the GRADE guidelines, when only a single study exists indicating significant findings for an outcome of interest (especially when the study is observational), the overall quality of the evidence is generally rated to be low or very low. ${ }^{38}$ Therefore, our process for prioritising nutrigenetic topics for evidence grading aimed to filter out specific nutrigenetic associations/interactions that would likely be deemed low or very low quality (based on, at minimum, lack of replication). Two authors (JK and VG) critically appraised the selected nutrigenetic interactions using the GRADE methodology, with one modification. ${ }^{38}$ The modified GRADE approach consisted of the additional consideration of biological plausibility whereby evidence was considered for upgrading if there was evidence of biological plausibility for the nutrigenetic interaction. Nutrigenetic interactions were grouped according to studies assessing the same SNP(s) / nutri-GRS and lipid/lipoprotein/apolipoprotein outcome and the quality of the body of evidence (studies with significant and non-significant results) was rated; this process was guided by the GRADE evidence profile, which included consideration of risk of bias, inconsistency, indirectness, imprecision, publication bias, plausible confounding, dose-response and other factors. ${ }^{38}$ For example, different sources of omega-3s (eg, EPA+DHAvs ALA; food sources vs supplementation) were taken into consideration when grading the evidence through the analysis of indirectness within the modified GRADE approach. ${ }^{38}{ }^{39}$ Risk of bias was assessed in each of the included interventional and observational studies using the National Institutes of Health Study Quality Assessment Tools, in line with recently published recommendations for risk of bias assessments. ${ }^{40}$ To assess measures of precision, coefficients of variation (CV) were calculated based on outcome means (mean change or absolute values-whichever was used for the analyses) and SD. In cases where standard errors of the mean were reported, these were converted to $\mathrm{SD}$ to calculate the $\mathrm{CV}$. The nutrigenetic interactions were each given an evidence grade of high, moderate, low or very low.

\section{RESULTS}

Figure 1 outlines the PRISMA flow diagram, which was used to guide the systematic review. Online supplemental tables 2 and 3 provide a summary of the 65 included studies. The results columns of online supplemental tables 2 and 3 (far right) indicate nutrigenetic findings that were statistically significant. There were many results from the included studies that were not statistically significant. It is important to highlight that any results related to the studies' analysed SNPs and outcomes of interest that were not statistically significant are not indicated in the results column. No studies explicitly reported that they followed STREGA guidelines. LD analysis of SNPs tested in different studies revealed strong LD in several SNPs from the FADS gene cluster (see table 2 note). As such, LD was taken into consideration in the selection of nutrigenetic interactions selected for evidence grading.

\section{Observational studies}

Of the 65 included studies, 23 were observational with the majority of these being cross-sectional, as outlined in online supplemental table 2. A total of 62221 participants were included in the observational studies. These studies assessed correlations among a number of different genetic variations and outcomes, with several studies assessing genetic variations in the FADS gene cluster, ${ }^{41-47}{ }^{T N F \alpha^{48-50}}$ and PPARa. ${ }^{51-53}$ Most studies $(\mathrm{n}=13)$ assessed total omega-3s. ${ }^{374146-485053-59}$ The intake and type of omega-3s, lipid/lipoprotein/apolipoprotein outcomes and associations revealed from these studies were variable as further detailed in online supplemental table 2. In the observational studies assessing genetic variation in the FADS gene cluster, some studies indicated significant gene-diet findings related to HDL-cholesterol, LDL-cholesterol, TG, total-cholesterol while other studies demonstrated no significant gene-diet interactions for these outcomes thus indicating notable inconsistency among the results, while considering that SNPs differed by studies. ${ }^{41-47}$ In 


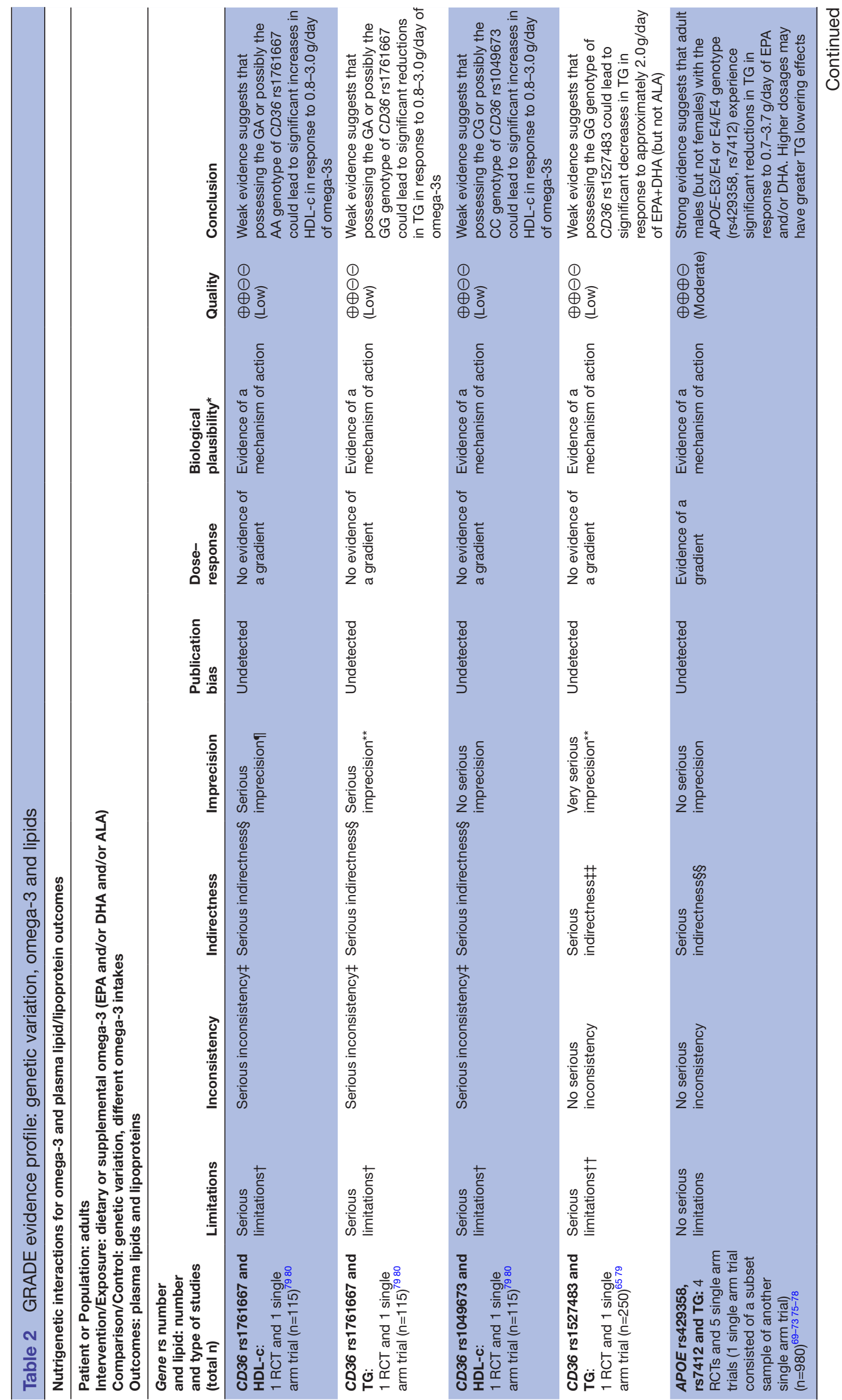




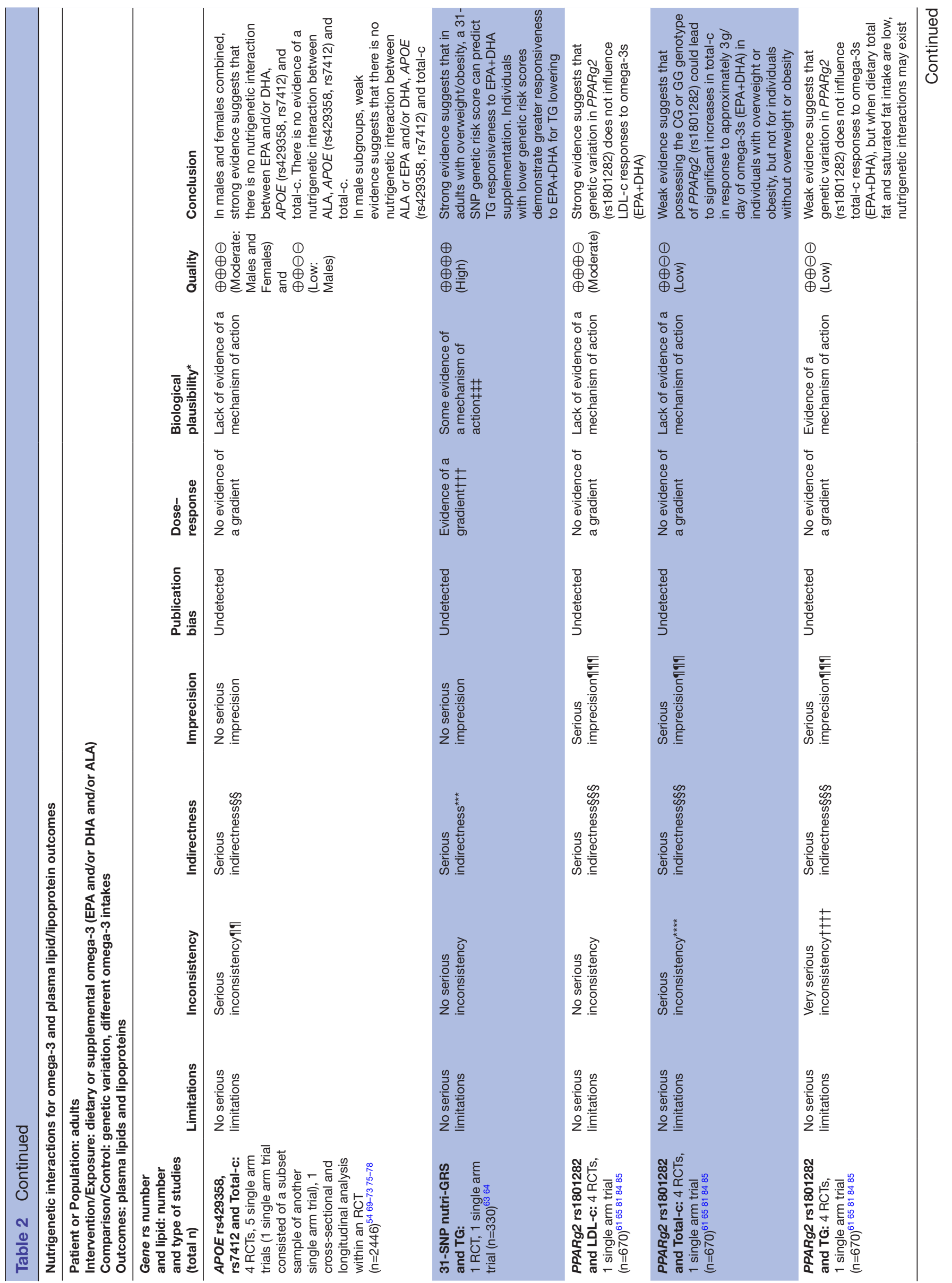



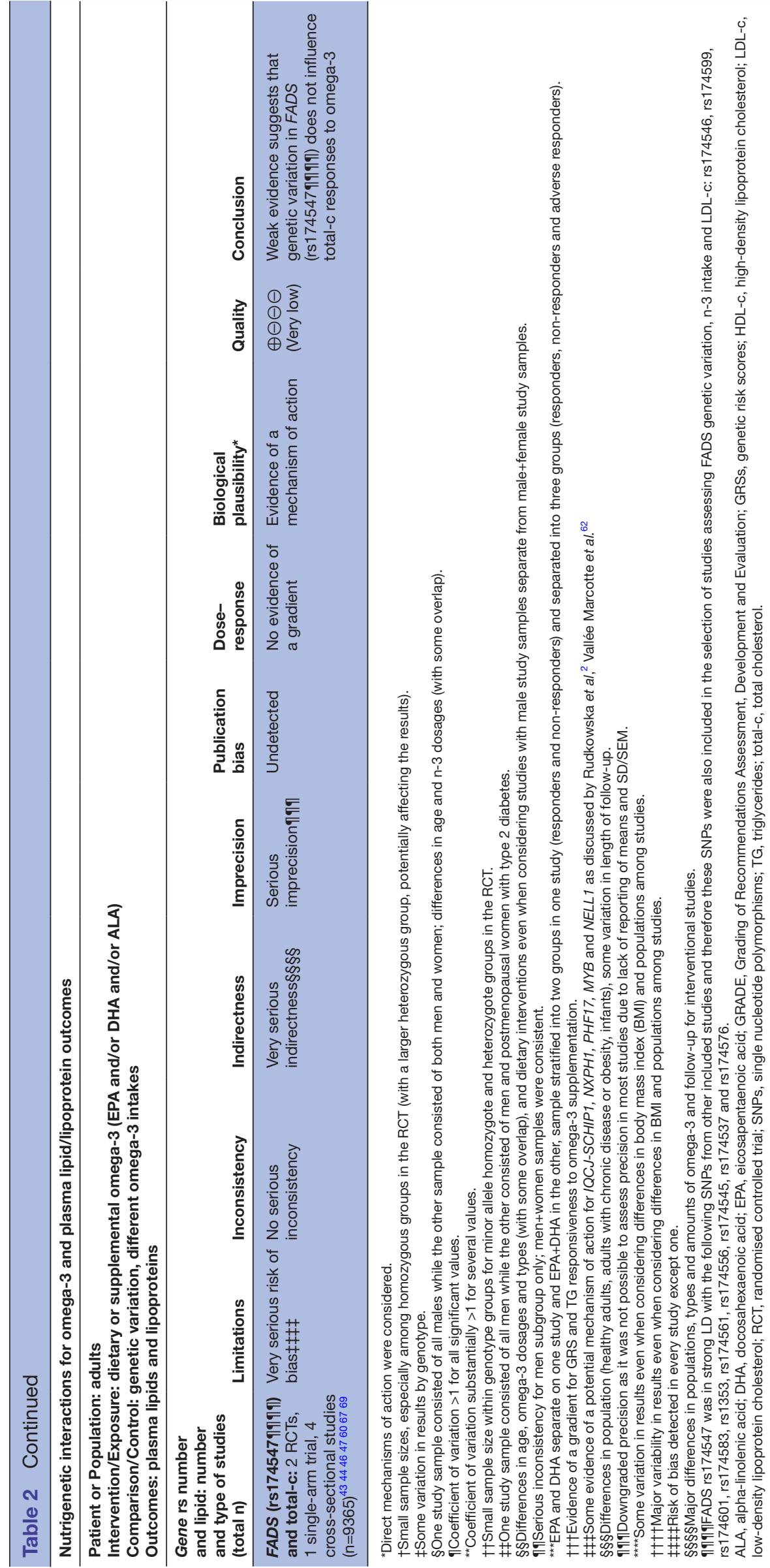
the observational studies focused on genetic variation in the $T N F \alpha$ gene, there was some evidence of a genediet relationship for omega-3 and LDL-cholesterol, total-cholesterol and total-cholesterol:HDL-cholesterol ratio, but again, results differed between studies. ${ }^{4-50}$ For gene-diet relationships and PPAR $\alpha$ genetic variation, individual studies indicated significant findings related to total-cholesterol, LDL-cholesterol, TG, apoC-III and LDL peak particle diameter. ${ }^{51-53}$ Comprehensive details of the observational studies are outlined in online supplemental table 2.

\section{Interventional studies}

Of the 65 included studies, 42 were interventional including 16 randomised trials. Non-randomised studies included single arm clinical trials and sequential non-randomised cross-over interventions. For interventional studies, there were 6225 participants on combining all sample sizes of the included studies. Again, these studies assessed relationships between a number of different genetic variants and study outcomes. In more recent years, several studies $(n=8)$ used a nutri-GRS or polygenic approaches ${ }^{260-66}$ given the plausibility that many gene-lipid/lipoprotein/apolipoprotein and omega-3 interactions are polygenic in nature. Numerous studies assessed genetic variations in the FADS gene cluster, ${ }^{606167-69}$ APOE, ${ }^{60-78} C^{6036,{ }^{65} 7980}$ PPARy 2 (62,67,8385) and PPARa. ${ }^{81-83}$ Among these studies, results related to significant gene-diet (omega-3) associations influencing lipid/lipoprotein outcomes were generally inconsistent except for APOE (rs429358 and rs7412), omega-3 and TG in males only, ${ }^{69-73}$ 75-78 and for a 31-SNP nutri-GRS, omega-3 and TG. ${ }^{6364}$ There was also consistent evidence to indicate a lack of association among PPARy 2 (rs1801282) genetic variation, EPA+DHAand LDL cholesterol. ${ }^{61} 65818485$ Most studies $(n=40)$ used supplemental EPA and/or DHA sources of omega-3s for the dietary intervention (see online supplemental table 3). The dosage/intake and type of omega-3s were variable with EPA and/or DHA dosages ranging from 0.5 to $3.7 \mathrm{~g} /$ day across different studies, and one study with an ALA intervention dosage of $8.1 \mathrm{~g} /$ day, as further detailed in online supplemental table 3 .

\section{Levels of evidence using GRADE}

A total of 25 articles were included in the evidence grading process, representing 11 unique nutrigenetic associations/ interactions as outlined in tables 2 and 3, and online supplemental table 4 . Through the modified GRADE process, it was determined that there is strong evidence (GRADE rating: moderate quality) for APOE genotypes (rs7412, rs429358), omega-3s and TG lowering in male adults only. ${ }^{69-73} 75-78$ This evidence suggests that adult males (but not females) with the APOE-E3/E4 or E4/E4 genotype (rs429358, rs7412) tend to experience significant reductions in TG in response to $0.7-3.7 \mathrm{~g} /$ day of EPA and/or DHA, with higher dosages demonstrating greater TG lowering effects. ${ }^{69-73} 75-78$ Furthermore, it was determined that there is strong evidence (GRADE rating: high quality) for using a 31-SNP nutri-GRS (detailed in online supplemental tables 5 and 6 ) to assess
Table 3 Summary of risk of bias across SNPs and outcomes following omega-3 exposure/intervention

\begin{tabular}{ll}
\hline Study & Risk of bias \\
\hline CD36, rs1761667 and HDL-c & \\
Dawczynski et al/ & $\ominus$ \\
Madden et al $^{80}$ & $\ominus$ \\
\hline
\end{tabular}

\section{CD36, rs1761667 and TG}

$\begin{array}{ll}\text { Dawczynski et a }\left.\right|^{80} & \Theta \\ \text { Madden et } a l^{79} & \Theta\end{array}$

\begin{tabular}{|c|c|}
\hline CD36, rs1049673 an & \\
\hline Dawczynski et a/ ${ }^{80}$ & $\Theta$ \\
\hline Madden et $a l^{79}$ & $\theta$ \\
\hline
\end{tabular}

\begin{tabular}{|c|c|}
\hline Zheng et $a l^{65}$ & $\oplus$ \\
\hline Madden et $a l^{79}$ & $\ominus$ \\
\hline \multicolumn{2}{|c|}{ ApoE, rs429358, rs7412 and TG } \\
\hline AbuMweis et al ${ }^{69}$ & $\ominus$ \\
\hline Carvalho-Wells et al ${ }^{70}$ & $\oplus$ \\
\hline Caslake et $a l^{71}$ & $\oplus$ \\
\hline Dang et $a l^{72}$ & $\oplus$ \\
\hline Jackson et al ${ }^{73}$ & $\Theta$ \\
\hline Minihane et $\mathrm{l}^{75}$ & $\oplus$ \\
\hline Olano-Martin et al ${ }^{76}$ & $\oplus$ \\
\hline Paschos et $a l^{77}$ & $\Theta$ \\
\hline Thifault et al ${ }^{78}$ & $\oplus$ \\
\hline \multicolumn{2}{|c|}{ ApoE, rs429358, rs7412 and total-c } \\
\hline AbuMweis et al ${ }^{69}$ & $\Theta$ \\
\hline Carvalho-Wells et al ${ }^{70}$ & $\oplus$ \\
\hline Caslake et $a l^{71}$ & $\oplus$ \\
\hline Dang et $a^{72}$ & $\oplus$ \\
\hline Fallaize et $a^{54}$ & $\Theta$ \\
\hline Jackson et al ${ }^{73}$ & $\ominus$ \\
\hline Minihane et $a l^{75}$ & $\oplus$ \\
\hline Olano-Martin et al ${ }^{76}$ & $\oplus$ \\
\hline Paschos et al ${ }^{77}$ & $\ominus$ \\
\hline Thifault et $a l^{78}$ & $\oplus$ \\
\hline
\end{tabular}

31-SNP nutri-GRS and TG

\begin{tabular}{|c|c|}
\hline Vallée Marcotte et $a^{63}$ & $\oplus$ \\
\hline Vallée Marcotte et al ${ }^{64}$ & $\oplus$ \\
\hline
\end{tabular}

PPARg2, rs1801282 and LDL-C

$\begin{array}{lr}\text { Binia et } a /^{81} & \oplus \\ \text { Harsløf et } a l^{61} & \oplus \\ \text { Itariu et } a l^{84} & \oplus \\ \text { Lindi et al/ }{ }^{85} & \oplus \\ \text { Zheng et } a l^{65} & \oplus\end{array}$

PPARg2, rs1801282 and total-c

Binia et $a l^{81}$

Harsløf et $\left.a\right|^{61}$

$\ominus$

$\oplus$ 


\begin{tabular}{|c|c|}
\hline Study & Risk of bias \\
\hline Itariu et al ${ }^{84}$ & $\oplus$ \\
\hline Lindi et $\mathrm{al}^{85}$ & $\Theta$ \\
\hline Zheng et $a l^{65}$ & $\oplus$ \\
\hline \multicolumn{2}{|c|}{ PPARg2, rs1801282 and TG } \\
\hline Binia et $a l^{81}$ & $\ominus$ \\
\hline Harsløf et al ${ }^{61}$ & $\oplus$ \\
\hline Itariu et al ${ }^{84}$ & $\oplus$ \\
\hline Lindi et al $^{85}$ & $\Theta$ \\
\hline Zheng et $a l^{65}$ & $\oplus$ \\
\hline \multicolumn{2}{|c|}{ FADS, rs174547 and total-c } \\
\hline AbuMweis et al ${ }^{69}$ & $\Theta$ \\
\hline Alsaleh et $a l^{60}$ & $\oplus$ \\
\hline Lu et $a l^{46}$ & $\ominus$ \\
\hline Standl et al/77 & $\Theta$ \\
\hline Dumont et $a l^{43}$ & $\ominus$ \\
\hline Dumont et $a l^{44}$ & $\Theta$ \\
\hline Roke and Mutch ${ }^{67}$ & $\ominus$ \\
\hline
\end{tabular}

$\oplus$ no serious risk of bias; $\Theta$ serious risk of bias; $\Theta \Theta$ very serious risk of bias (for study design type using NIH Study Quality Assessment Tools).

GRSs, genetic risk scores; HDL-c, high-density lipoprotein cholesterol; LDL-c, low-density lipoprotein cholesterol; SNPs, single nucleotide polymorphisms; TG, triglycerides; total-c, total cholesterol.

the effectiveness of omega-3s for TG lowering in adults with overweight/obesity in various ethnicities. ${ }^{63} 64$ The evidence suggests that in adults with overweight/obesity, lower GRSs demonstrate greater responsiveness to omega-3 supplementation. ${ }^{63} 64$

All other evidence that was evaluated was determined to be weak (GRADE rating: low or very low quality), as further detailed in table 2. Imprecision, indirectness and inconsistency were common reasons for downgrading the evidence (refer to table 2 note). There was evidence for a plausible mechanism of action for most of the nutrigenetic interactions that were graded; evidence of a dose-response was less common.

\section{DISCUSSION}

Overall, this systematic review found strong evidence (ie, GRADE ratings: moderate and high-quality evidence) for only a limited amount of evidence in this area: $A P O E$ (rs429358 and rs7412) genotypes and TG responsiveness to omega-3s in men, and a 31-SNP nutri-GRS and TG responsiveness to omega-3s in adults with overweight/ obesity. Limited evidence exists for individual geneticbased responsiveness of omega-3s on apolipoprotein and/or LDL particle size, with no studies from the present comprehensive review meeting the criteria for evidence grading. This highlights the need for more replication studies in these areas. While more research exists on omega-3 responsiveness for other lipid outcomes such as total-c, HDL-c and LDL-c, the level of evidence for nutrigenetic interactions related to these outcomes remains low. Again, more studies are needed related to these outcomes, including replication studies of previously identified nutrigenetic interactions. These studies should first replicate the interventions (ie, use the same type and amount of omega-3s as the original study), and recruit samples with similar characteristics to the original study. Once replication is established, research should then seek to expand the population studied to improve generalisability and explore the effectiveness of different interventions (ie, different formulations and doses of omega-3s). The variability of the interventions and sample sizes in the studies conducted to date often resulted in the quality of evidence being downgraded (see table 2). It should also be noted that study heterogeneity precluded the ability to conduct a meta-analysis. Thus, the GRADE approach worked well for evaluating the quality of the evidence given that this approach takes into consideration several factors when determining the quality of evidence such as risk of bias, indirectness of evidence, inconsistency or results, imprecision and publication bias. ${ }^{38}$

It is important to note that our results demonstrating strong evidence for interactions between $A P O E$ genotypes and lipid responses to omega-3s have notable ethical implications. Compared with non-carriers, carriers of APOE-E4 have a 15 times greater risk of developing Alzheimer's disease. ${ }^{86}$ Moreover, APOE genotypes are significantly associated with CVD risk including risk of coronary artery disease and hyperlipidaemia. ${ }^{87-89}$ Interestingly, the pathology of Alzheimer's disease has been linked to cardiovascular mechanisms. ${ }^{86}$ Future research should explore nutrigenetic interactions, with risk of developing Alzheimer's disease as the study endpoint/outcome of interest. Despite the current lack of knowledge about how diet may play a role in mitigating the genetic-based risk of Alzheimer's disease, several potentially modifiable risk factors account for around $40 \%$ of dementia and Alzheimer's disease globally, ${ }^{90}$ and the link between Alzheimer's disease risk and $A P O E$ is well-established. ${ }^{91}$ Therefore, despite the strong scientific validity identified in the present review, there are other factors that must be considered before this test should be implemented in a practice setting; these include ethical, legal and social implications. $^{92}$

In addition, our finding of strong evidence for $A P O E$ genotypes and TG responsiveness to omega-3s in men but not women speaks to the importance of taking biological sex into account in nutrigenetics research. The importance of this has been further highlighted elsewhere, where it has been noted that the results of nutrition and nutrigenetic research may differ in men and women. ${ }^{93}$ For example, UDP-glucuronidation isoenzyme expression profiles have been demonstrated to be regulated by sex hormones, and thus sex-specific differences in glucuronidation of resveratrol have been observed. ${ }^{94}$ As more studies are completed, researchers may find that 
certain nutrigenetic interactions differ depending on biological sex, ethnicity, age or other factors, similar to our findings on $A P O E$, omega-3s and TG in which there was robust evidence of a nutrigenetic interaction in males only. Researchers may also find explanations for this, which are currently poorly understood. In general, it is becoming increasingly recognised that health-related responses to different interventions may vary based on biological sex; this is an important consideration of personalised nutrition. ${ }^{93}$ Nutrigenetic research often groups men and women together, but stratifying based on biological sex could provide further insights for specific nutrigenetic interactions and could also help explain why some replication studies have had conflicting findings. ${ }^{93}$ Moreover, biomedical research in general historically has been conducted more in men than women. However, such research findings are often generalised to women despite limited research conducted in samples of women, which is problematic for a number of reasons. ${ }^{95}$ In the present review, the evidence was strong for the $A P O E$ findings in men only, but not women in part because there were more studies conducted in men. Specifically, there were five studies conducted in men and women (combined), ${ }^{6971729697}$ and four studies conducted in samples of only men, ${ }^{73} 767798$ yet no studies conducted in samples of only women. This brings to light important issues of equity and warrants further discussion and consideration.

As research continues to develop, it appears likely that lipid and lipoprotein responses are polygenic in nature. Therefore, future research should consider using nutriGRSs or other polygenic methods of assessing responsiveness to nutrition interventions. This work should use unbiased approaches or non-hypothesis driven approach to derive nutri-GRSs, such as establishing them from genetic-wide association studies. In addition to the two nutri-GRS studies meeting the criteria for evidence grading in the current work, ${ }^{6364}$ a modified version of the 31-SNP GRS was tested in men and women in the FINGEN study, using 23 of the $31 \mathrm{SNPs} .{ }^{63}$ While this did not meet our inclusion criteria for evidence grading given that a different GRS was used, the 23-SNP GRS was significantly associated with TG responsiveness to omega-3 supplementation in this population as well, providing further evidence for the scientific validity of this nutrigenetic interaction. $^{63}$

While we used a modified version of the GRADE approach (with the additional consideration of biological plausibility) to evaluate the body of evidence, several tools are available for evaluating the quality of scientific evidence. In 2017, Grimaldi et al proposed a set of guidelines to assess the scientific validity of genotype-based dietary advice. ${ }^{30}$ While we originally intended to use these guidelines for assessing the evidence, we came across some limitations that ultimately led us to use the GRADE guidelines. Specifically, Grimaldi et al suggested that only studies that include STREGA guidelines should be included in the assessment of scientific validity. ${ }^{30}$ However, limiting the evidence to only these studies could result in several important studies being missed. In the present review, none of the included studies explicitly indicated that they followed STREGA guidelines. In addition, it was recommended by Grimaldi et al to use STREGA guidelines to assess risk of bias. ${ }^{30}$ However, the STREGA checklist is only intended for observational genetic association studies-not interventional research. ${ }^{99}$ In the present review, 42 of the 65 included studies were interventional $(65 \%)$ (online supplemental table 3 ). In addition, the STREGA guidelines are intended to improve the transparency and adequate reporting of genetic association studies, but it is not intended to be used as a study quality assessment tool. ${ }^{99}$ However, Grimaldi et al nicely highlighted the importance of understanding the nature of the genetic variation, at a functional level, when assessing scientific validity. ${ }^{30}$ This is not included in the standard GRADE approach but is an important niche component of nutrigenetic evidence evaluation. As such, an analysis of functional SNPs (biological plausibility) was included as an additional component of the standard GRADE process, as indicated in the Methods section. Overall, we found that the methods used in this systematic review were effective and can be used to synthesise and evaluate nutrigenetic studies assessing other gene-nutrienthealth outcome interactions.

The additional consideration of functional SNPs to the standard GRADE approach helped to strengthen this review, as biological mechanistic evidence can help ensure that study findings did not occur by chance alone; this is a standard component of evidence evaluation frameworks in medical genetics. ${ }^{100} 101$ Transcriptomic and pathway analyses can help inform the direction of future nutrigenetic studies by generating hypotheses about the impact of specific genetic variations on varying responses to nutrition on health-related outcomes. For example, using transcriptomics and pathway analyses to identify changes in lipid metabolism following omega-3 supplementation, Rudkowska and colleagues identified six genes expressed in opposite directions between responders and nonresponders to omega-3 supplementation for TG lowering: FADS2, PLA2G4A, ALOX15, PEMT, MGLL and GPAM. ${ }^{102}$ Tremblay $e t$ al then built on this knowledge and discovered that PLA2G6 rs132989, PLA2G7 rs679667, PLA2G2D rs12045689, PLA2G4A rs10752979 and rs1160719 together explained $5.9 \%$ of post-omega-3 supplementation TG levels, with several individual PLA2G4A SNPs also having a significant impact on the TG lowering effect of omega-3 supplementation. ${ }^{103}$ Others have built on this mechanistic knowledge as well. ${ }^{104}$ Future research should now seek to replicate this work given that we found that there have been no replication studies completed and thus, this research ${ }^{103} 104$ did not meet the criteria for evidence grading.

In the current body of literature, there are some limitations that should be highlighted. Given the variability in allele frequencies for each SNP, it should be noted that study limitations can arise with small sample sizes whereby 
some genotype groups may not be adequately powered to detect significant differences. For example, Dawczynski et al detected significant changes in TG among the GA genotype group of CD36 rs1761667 ( $\mathrm{n}=18)$ in response to omega-3s but neither of the homozygote groups (AA: $\mathrm{n}=8$, GG: $\mathrm{n}=7$ ) exhibited a significant difference, despite similar directions and magnitudes of effect among the GA and GG genotypes. ${ }^{80}$ It is thus possible that this study was not adequately powered. Some researchers aim to mitigate this issue of small numbers by grouping minor allele carriers together (ie, heterozygotes+homozygotes for the minor allele) ${ }^{67}$ However, such an approach precludes the possibility to detect an allele-dosage effect. From a physiological perspective, an allele dosage effect would be expected whereby a significant change among a heterozygote group would likely be accompanied by a significant change in one of the homozygote groups but with an even greater magnitude of the effect. This consideration highlights the importance of having an adequately powered sample size, while factoring in the prevalence of each genotype.

While single SNP research provides important information about individual gene-nutrient interactions, the results of this review indicate that individual responses to omega-3s for altering lipids, lipoproteins and apolipoproteins appear to be polygenic in nature. Thus, we encourage researchers to further explore the use of nutriGRSs to improve the accuracy of genetic-based predictions. See, for example, the work of Vallée Marcotte $e t$ $a l$, which obtained a high-quality evidence grade in the present review. ${ }^{634}$ This is further exemplified in the analyses recently conducted by Chen $e t a l,{ }^{41}$ which has yet to be replicated and thus was not selected for evidence grading.

The present analysis of scientific validity provides an important first step towards the development of clinical practice guidelines for genetic-based responses to dietary intake, which have been recently published. ${ }^{105}$ With questionable and variable scientific validity of existing consumer nutrigenetic tests, the development of clinical practice guidelines is an important accomplishment as these can be used by healthcare professionals (HCPs) and industry alike to help promote evidence-based practice in personalised nutrition. Ideally, industry should use clinical practice guidelines to inform the nutrigenetic associations and related dietary recommendations included in their reports. Decision aids can also be useful to guide clinical practice for HCPs, ${ }^{106}$ and future research should seek to develop a decision aid related to omega-3s and lipid/lipoprotein outcomes based on genetic variation.

It should be noted that there are some limitations to the present systematic review. First, the literature was searched up until August 2020; as such, any articles published after this date were not included. Furthermore, certain nutrigenetic associations/interactions were prioritised for evidence grading therefore evidence grades remain unknown for numerous associations/interactions included in the narrative synthesis. However, evidence from a single study typically results in an evidence grade of low or very low using the GRADE approach, ${ }^{38}$ therefore it is unlikely that any/many nutrigenetic associations/ interactions with strong scientific validity (which could be considered for use in clinical practice) were missed. Future research groups may choose to instead select a specific SNP or nutri-GRS as the focus of future systematic reviews. The specific SNP or nutri-GRS chosen may be selected based on the results of a preliminary scoping review. This would allow for all articles included in the systematic review to undergo evidence grading. The approach taken in the present review was more comprehensive, but has its limitations as stated earlier.

Overall, we have provided a comprehensive overview of the body of evidence related to nutrigenetics, omega-3s and plasma lipids/lipoproteins/apolipoproteins, while providing an overview of levels of evidence in this field. To our knowledge, this is the first systematic review with GRADE evidence evaluation in the broader field of nutrigenetics. The results of this work should be used in clinical practice guideline development, to ultimately guide evidence-based practice in personalised nutrition and move this emerging field forward.

\section{Author affiliations}

${ }^{1}$ Université Laval, Centre Nutrition, Santé et Société (NUTRISS), Institut sur la Nutrition et les Aliments Fonctionnels (INAF) Quebec, Quebec City, Quebec, Canada

${ }^{2}$ Universite Laval, School of Nutrition, Quebec City, Quebec, Canada

${ }^{3}$ Department of Nutrition, University of Montréal, Montréal, Quebec, Canada ${ }^{4}$ Research Centre, Sainte-Justine University Health Centre, Montréal, Quebec, Canada

${ }^{5}$ Department of Human Health and Nutritional Sciences, University of Guelph, Guelph, Ontario, Canada

${ }^{6}$ Department of Kinesiology, Université Laval, Quebec City, Quebec, Canada ${ }^{7}$ Endocrinology and Nephrology Unit, CHU de Québec - Université Laval Research Center, Quebec City, Quebec, Canada

${ }^{8}$ Library, Université Laval, Quebec City, Quebec, Canada

Contributors M-CV and JK conceptualised the review and are responsible for the overall content as guarantors. GMS was responsible for the search strategy, in collaboration with JK, M-CV, SD and VG. JK and VG were responsible for article screening and selection, summarising, evidence grading and developing a draft of the systematic review. The first systematic review draft underwent revisions from SD and M-CV, who provided overall supervision for the project. Following this, JK, VG, VM, DMM, JR, IR, GMS, SD, and M-CV served as scientific advisors and reviewed and revised the full-text manuscript. JK wrote the first draft of the manuscript. JK, VG, VM, DMM, JR, IR, GMS, SD and M-CV reviewed, revised and approved the final manuscript.

Funding This project was supported through a pilot projects grant from INAF. JK was supported through postdoctoral fellowships from CIHR (\#430907), NUTRISS and INAF. M-CV holds a Canada Research Chair in Genomics Applied to Nutrition and Metabolic Health.

Competing interests None declared.

Patient consent for publication Not applicable.

Ethics approval This study does not involve human participants.

Provenance and peer review Not commissioned; externally peer reviewed.

Data availability statement Data are available upon reasonable request.

Supplemental material This content has been supplied by the author(s). It has not been vetted by BMJ Publishing Group Limited (BMJ) and may not have been peer-reviewed. Any opinions or recommendations discussed are solely those of the author(s) and are not endorsed by BMJ. BMJ disclaims all liability and responsibility arising from any reliance placed on the content. Where the content 
includes any translated material, BMJ does not warrant the accuracy and reliability of the translations (including but not limited to local regulations, clinical guidelines, terminology, drug names and drug dosages), and is not responsible for any error and/or omissions arising from translation and adaptation or otherwise.

Open access This is an open access article distributed in accordance with the Creative Commons Attribution Non Commercial (CC BY-NC 4.0) license, which permits others to distribute, remix, adapt, build upon this work non-commercially, and license their derivative works on different terms, provided the original work is properly cited, appropriate credit is given, any changes made indicated, and the use is non-commercial. See: http://creativecommons.org/licenses/by-nc/4.0/.

\section{ORCID iDs}

Justine Keathley http://orcid.org/0000-0002-9176-9645

Gabriela Magdalena Sofian http://orcid.org/0000-0002-2918-8049

Marie-Claude Vohl http://orcid.org/0000-0002-7017-5848

\section{REFERENCES}

1 Barquera S, Pedroza-Tobías A, Medina C, et al. Global overview of the epidemiology of atherosclerotic cardiovascular disease. Arch Med Res 2015;46:328-38.

2 Rudkowska I, Guénard F, Julien P, et al. Genome-Wide association study of the plasma triglyceride response to an $n-3$ polyunsaturated fatty acid supplementation. J Lipid Res 2014;55:1245-53.

3 Rizzi F, Conti C, Dogliotti E, et al. Interaction between polyphenols intake and PON1 gene variants on markers of cardiovascular disease: a nutrigenetic observational study. J Trans/ Med 2016;14:186.

4 Zhang X, Qi Q, Zhang C, et al. Fto genotype and 2-year change in body composition and fat distribution in response to weight-loss diets: the pounds lost trial. Diabetes 2012;61:3005-11.

5 Merritt DC, Jamnik J, El-Sohemy A. FTO genotype, dietary protein intake, and body weight in a multiethnic population of young adults: a cross-sectional study. Genes Nutr 2018;13:4.

6 Vallée Marcotte B, Cormier H, Garneau V, et al. Nutrigenetic testing for personalized nutrition: an evaluation of public perceptions, attitudes, and concerns in a population of French Canadians. Lifestyle Genom 2018;11:155-62.

7 Vallée Marcotte B, Cormier H, Garneau V, et al. Current knowledge and interest of French Canadians regarding nutrigenetics. Genes Nutr 2019;14:5.

8 Caulfield T, McGuire AL. Direct-To-Consumer genetic testing: perceptions, problems, and policy responses. Annu Rev Med 2012;63:23-33.

9 Horne J, Gilliland J, Madill J, et al. A critical examination of legal and ethical considerations for nutrigenetic testing with recommendations for improving regulation in Canada: from science to consumer. J Law Biosci 2020;7:Isaa003.

10 Görman U, Mathers JC, Grimaldi KA, et al. Do we know enough? A scientific and ethical analysis of the basis for genetic-based personalized nutrition. Genes Nutr 2013;8:373-81.

11 Harris WS. Stearidonic acid as a 'pro-eicosapentaenoic acid'. Curr Opin Lipidol 2012;23:30-4.

12 Shahidi F, Ambigaipalan P. Omega-3 polyunsaturated fatty acids and their health benefits. Annu Rev Food Sci Technol 2018;9:345-81.

$13 \mathrm{Hu}$ Y, Hu FB, Manson JE. Marine omega-3 supplementation and cardiovascular disease: an updated meta-analysis of 13 randomized controlled trials involving 127477 participants. J Am Heart Assoc 2019;8:e013543.

14 Abdelhamid AS, Brown TJ, Brainard JS, et al. Omega-3 fatty acids for the primary and secondary prevention of cardiovascular disease. Cochrane Database Syst Rev 2018;304

15 Jones PJH, Senanayake VK, Pu S, et al. DHA-enriched higholeic acid canola oil improves lipid profile and lowers predicted cardiovascular disease risk in the canola oil multicenter randomized controlled trial. Am J Clin Nutr 2014;100:88-97.

16 Ballantyne CM, Bays HE, Kastelein JJ, et al. Efficacy and safety of eicosapentaenoic acid ethyl ester (AMR101) therapy in statintreated patients with persistent high triglycerides (from the anchor study). Am J Cardiol 2012;110:984-92.

17 Davidson MH, Stein EA, Bays HE, et al. Efficacy and tolerability of adding prescription omega- 3 fatty acids $4 \mathrm{~g} / \mathrm{d}$ to simvastatin $40 \mathrm{mg} / \mathrm{d}$ in hypertriglyceridemic patients: an 8-week, randomized, double-blind, placebo-controlled study. Clin Ther 2007;29:1354-67.

18 Bradberry JC, Hilleman DE. Overview of omega-3 fatty acid therapies. P T 2013;38:681-91.
19 Skulas-Ray AC, Alaupovic P, Kris-Etherton PM, et al. DoseResponse effects of marine omega-3 fatty acids on apolipoproteins, apolipoprotein-defined lipoprotein subclasses, and Lp-PLA2 in individuals with moderate hypertriglyceridemia. J Clin Lipidol 2015;9:360-7.

20 Lee MW, Park JK, Hong JW, et al. Beneficial effects of omega-3 fatty acids on low density lipoprotein particle size in patients with type 2 diabetes already under statin therapy. Diabetes Metab J 2013;37:207-11.

21 Bouwens M, van de Rest O, Dellschaft N, et al. Fish-Oil supplementation induces antiinflammatory gene expression profiles in human blood mononuclear cells. Am J Clin Nutr 2009;90:415-24.

22 Rudkowska I, Paradis A-M, Thifault E, et al. Transcriptomic and metabolomic signatures of an $n-3$ polyunsaturated fatty acids supplementation in a normolipidemic/normocholesterolemic Caucasian population. J Nutr Biochem 2013;24:54-61.

23 Merched AJ, Chan L. Nutrigenetics and nutrigenomics of atherosclerosis. Curr Atheroscler Rep 2013;15:328.

24 Madden J, Williams CM, Calder PC, et al. The impact of common gene variants on the response of biomarkers of cardiovascular disease (CVD) risk to increased fish oil fatty acids intakes. Annu Rev Nutr 2011:31:203-34

25 Cave C, Hein N, Smith LM, et al. Omega-3 long-chain polyunsaturated fatty acids intake by ethnicity, income, and education level in the United States: NHANES 2003-2014. Nutrients 2020;12. doi:10.3390/nu12072045. [Epub ahead of print: $09 \mathrm{Jul}$ 2020].

26 World Health Organization. Joint FAO/WHO expert consultation on fats and fatty acids in human nutrition, 2008. Available: http://www. who.int/nutrition/topics/FFA_interim_recommendations/en/

27 Fats and fatty acids in human nutrition | Karger book, 2021. Available: https://www.karger.com/Book/Home/251867

28 Horne J, Madill J, O'Connor C, et al. A systematic review of genetic testing and lifestyle behaviour change: are we using high-quality genetic interventions and considering behaviour change theory? Lifestyle Genom 2018;11:49-63.

29 Corella D, Ordovás JM. Interactions between dietary $n-3$ fatty acids and genetic variants and risk of disease. Br J Nutr 2012;107 Suppl 2:S271-83. doi:10.1017/S0007114512001651

30 Grimaldi KA, van Ommen B, Ordovas JM, et al. Proposed guidelines to evaluate scientific validity and evidence for genotype-based dietary advice. Genes Nutr 2017;12:35.

31 Khan KS, Kunz R, Kleijnen J, et al. Five steps to conducting a systematic review. J R Soc Med 2003;96:118-21.

32 PRISMA. PRISMA: transparent reporting of systematic reviews and meta-analyses, 2015. Available: http://www.prisma-statement.org/

33 Pollock A, Berge E. How to do a systematic review. Int J Stroke 2018:13:138-56.

34 Dekkers OM, Vandenbroucke JP, Cevallos M, et al. COSMOS-E: guidance on conducting systematic reviews and meta-analyses of observational studies of etiology. PLoS Med 2019;16:e1002742.

35 Grade Handbook. Available: https://gdt.gradepro.org/app/ handbook/handbook.html [Accessed 29 Sep 2020].

36 SNiPA - a single nucleotide polymorphisms annotator and browser, 2020. Available: https://snipa.helmholtz-muenchen.de/snipa3/index. php?task=proxy_search

37 Hosseini-Esfahani F, Mirmiran P, Koochakpoor G, et al. Some dietary factors can modulate the effect of the zinc transporters 8 polymorphism on the risk of metabolic syndrome. Sci Rep 2017;7:1649.

38 Grade Handbook. Available: https://gdt.gradepro.org/app/ handbook/handbook.html\#h.dce0ghnajwsm [Accessed 3 Apr 2020].

39 Murad MH, Mustafa RA, Schünemann HJ, et al. Rating the certainty in evidence in the absence of a single estimate of effect. Evid Based Med 2017;22:85-7.

40 Ma L-L WY-Y, Yang Z-H, Huang D. Methodological quality (risk of bias) assessment tools for primary and secondary medical studies: what are they and which is better? Mil Med Res 2020;7.

41 Chen Y, Estampador AC, Keller M, et al. The combined effects of FADS gene variation and dietary fats in obesity-related traits in a population from the far North of Sweden: the glacier study. Int $J$ Obes 2019:43:808-20.

42 Ching YK, Chin YS, Appukutty M, et al. Interaction of dietary linoleic acid and $\alpha$-linolenic acids with rs174547 in FADS1 gene on metabolic syndrome components among vegetarians. Nutrients 2019;11:1686.

43 Dumont J, Huybrechts I, Spinneker A, et al. Fads1 genetic variability interacts with dietary $\alpha$-linolenic acid intake to affect serum nonHDL-cholesterol concentrations in European adolescents. J Nutr 2011:141:1247-53. 
44 Dumont J, Goumidi L, Grenier-Boley B, et al. Dietary linoleic acid interacts with FADS1 genetic variability to modulate HDLcholesterol and obesity-related traits. Clin Nutr 2018;37:1683-9.

45 Hellstrand S, Sonestedt E, Ericson U, et al. Intake levels of dietary long-chain PUFAs modify the association between genetic variation in FADS and LDL-C. J Lipid Res 2012;53:1183-9.

46 Lu Y, Feskens EJ, Dollé ME, et al. Dietary n-3 and n-6 polyunsaturated fatty acid intake interacts with FADS1 genetic variation to affect total and HDL-cholesterol concentrations in the Doetinchem cohort study. Am J Clin Nutr 2010;92:258-65.

47 Standl M, Lattka E, Stach B, et al. FADS1 FADS2 gene cluster, PUFA intake and blood lipids in children: results from the GINIplus and LISAplus studies. PLoS One 2012;7:e37780.

48 Fontaine-Bisson B, Wolever TMS, Chiasson J-L, et al. Genetic polymorphisms of tumor necrosis factor-alpha modify the association between dietary polyunsaturated fatty acids and fasting HDL-cholesterol and apo A-I concentrations. Am J Clin Nutr 2007;86:768-74.

49 Joffe YT, van der Merwe L, Carstens M, et al. Tumor necrosis factoralpha gene $-308 \mathrm{G} / \mathrm{A}$ polymorphism modulates the relationship between dietary fat intake, serum lipids, and obesity risk in black South African women. J Nutr 2010;140:901-7.

50 Joffe YT, van der Merwe L, Evans J, et al. The tumor necrosis factor- $\alpha$ gene $-238 \mathrm{G}>\mathrm{A}$ polymorphism, dietary fat intake, obesity risk and serum lipid concentrations in black and white South African women. Eur J Clin Nutr 2012;66:1295-302.

51 Tai ES, Corella D, Demissie S, et al. Polyunsaturated fatty acids interact with the PPARA-L162V polymorphism to affect plasma triglyceride and apolipoprotein C-III concentrations in the Framingham heart study. J Nutr 2005;135:397-403.

52 Volcik KA, Nettleton JA, Ballantyne CM, et al. Peroxisome proliferator-activated receptor [alpha] genetic variation interacts with n-6 and long-chain n-3 fatty acid intake to affect total cholesterol and LDL-cholesterol concentrations in the Atherosclerosis Risk in Communities Study. Am J Clin Nutr 2008;87:1926-31.

53 Bouchard-Mercier A, Godin G, Lamarche B. Effects of peroxisome proliferator-activated receptors, dietary fat intakes and Gene-Diet interactions on peak particle diameters of low-density lipoproteins. $J$ Nutr Nutr 2011:4:36-48.

54 Fallaize R, Celis-Morales C, Macready AL, et al. The effect of the apolipoprotein $\mathrm{E}$ genotype on response to personalized dietary advice intervention: findings from the Food4Me randomized controlled trial. Am J Clin Nutr 2016;104:827-36.

55 Fontaine-Bisson B, Wolever TMS, Connelly PW, et al. Nf-kappaB -94Ins/Del ATTG polymorphism modifies the association between dietary polyunsaturated fatty acids and HDL-cholesterol in two distinct populations. Atherosclerosis 2009;204:465-70.

56 Jang HB, Hwang J-Y, Park JE, et al. Intake levels of dietary polyunsaturated fatty acids modify the association between the genetic variation in PCSK5 and HDL cholesterol. J Med Genet 2014:51:782-8.

57 Lai C-Q, Corella D, Demissie S, et al. Dietary intake of n-6 fatty acids modulates effect of apolipoprotein A5 gene on plasma fasting triglycerides, remnant lipoprotein concentrations, and lipoprotein particle size: the Framingham heart study. Circulation 2006;113:2062-70.

58 Richardson K, Louie-Gao Q, Arnett DK, et al. The PLIN4 variant rs8887 modulates obesity related phenotypes in humans through creation of a novel miR-522 seed site. PLoS One 2011;6:e17944.

59 Warodomwichit D, Arnett DK, Kabagambe EK, et al. Polyunsaturated fatty acids modulate the effect of TCF7L2 gene variants on postprandial lipemia. J Nutr 2009;139:439-46.

60 AISaleh A, Maniou Z, Lewis FJ, et al. Genetic predisposition scores for dyslipidaemia influence plasma lipid concentrations at baseline but not the changes after controlled intake of n-3 polyunsaturated fatty acids. Genes Nutr 2014;9:412.

61 Harsløf LBS, Damsgaard CT, Hellgren LI, et al. Effects on metabolic markers are modified by PPARG2 and COX2 polymorphisms in infants randomized to fish oil. Genes Nutr 2014;9:396.

62 Vallée Marcotte B, Guénard F, Cormier H, et al. Plasma triglyceride levels may be modulated by gene expression of IQCJ, NXPH1, PHF17 and Myb in humans. Int J Mol Sci 2017;18. doi:10.3390/ ijms18020257. [Epub ahead of print: 26 Jan 2017]

63 Vallée Marcotte B, Guénard F, Lemieux S, et al. Fine mapping of genome-wide association study signals to identify genetic markers of the plasma triglyceride response to an omega-3 fatty acid supplementation. Am J Clin Nutr 2019;109:176-85.

64 Vallée Marcotte B, Allaire J, Guénard F, et al. Genetic risk prediction of the plasma triglyceride response to independent supplementations with eicosapentaenoic and docosahexaenoic acids: the comparED study. Genes Nutr 2020;15:10.
65 Zheng J-S, Chen J, Wang L, et al. Replication of a Gene-Diet interaction at CD36, NOS3 and PPARG in response to omega-3 fatty acid supplements on blood lipids: a double-blind randomized controlled trial. EBioMedicine 2018;31:150-6.

66 Vallée Marcotte B, Guénard F, Marquis J, et al. Genetic risk score predictive of the plasma triglyceride response to an omega-3 fatty acid supplementation in a Mexican population. Nutrients 2019;11:737.

67 Roke K, Mutch DM. The role of FADS1/2 polymorphisms on cardiometabolic markers and fatty acid profiles in young adults consuming fish oil supplements. Nutrients 2014;6:2290-304.

68 Cormier H, Rudkowska I, Paradis A-M, et al. Association between polymorphisms in the fatty acid desaturase gene cluster and the plasma triacylglycerol response to an n-3 PUFA supplementation. Nutrients 2012;4:1026-41.

69 AbuMweis SS, Panchal SK, Jones PJH. Triacylglycerol-Lowering effect of docosahexaenoic acid is not influenced by singlenucleotide polymorphisms involved in lipid metabolism in humans. Lipids 2018:53:897-908.

70 Carvalho-Wells AL, Jackson KG, Lockyer S, et al. Apoe genotype influences triglyceride and C-reactive protein responses to altered dietary fat intake in UK adults. Am J Clin Nutr 2012;96:1447-53.

71 Caslake MJ, Miles EA, Kofler BM, et al. Effect of sex and genotype on cardiovascular biomarker response to fish oils: the FINGEN study. Am J Clin Nutr 2008;88:618-29.

72 Dang TM, Conway V, Plourde M. Disrupted fatty acid distribution in HDL and LDL according to apolipoprotein E allele. Nutrition 2015;31:807-12.

73 Jackson KG, Lockyer S, Carvalho-Wells AL, et al. Dietary fat manipulation has a greater impact on postprandial lipid metabolism than the apolipoprotein $\mathrm{E}$ (epsilon) genotype-insights from the SATgenc study. Mol Nutr Food Res 2012;56:1761-70.

74 Jackson KG, Lockyer S, Carvalho-Wells AL, et al. Apolipoprotein E (epsilon) genotype has a greater impact on apoB-48 than apoB-100 responses to dietary fat manipulation-insights from the SATgene study. Mol Nutr Food Res 2017;61:1600688.

75 Minihane AM, Khan S, Leigh-Firbank EC, et al. Apoe polymorphism and fish oil supplementation in subjects with an atherogenic lipoprotein phenotype. Arterioscler Thromb Vasc Biol 2000;20:1990-7.

76 Olano-Martin E, Anil E, Caslake MJ, et al. Contribution of apolipoprotein $\mathrm{E}$ genotype and docosahexaenoic acid to the LDLcholesterol response to fish oil. Atherosclerosis 2010;209:104-10.

77 Paschos GK, Yiannakouris N, Rallidis LS, et al. Apolipoprotein E genotype in dyslipidemic patients and response of blood lipids and inflammatory markers to alpha-linolenic acid. Angiology 2005;56:49-60.

78 Thifault E, Cormier H, Bouchard-Mercier A. Effects of age, sex, body mass index and APOE genotype on cardiovascular biomarker response to an n-3 polyunsaturated fatty acid supplementation. $J$ Nutr Nutr 2013;6:73-82.

79 Madden J, Carrero JJ, Brunner A, et al. Polymorphisms in the CD36 gene modulate the ability of fish oil supplements to lower fasting plasma triacyl glycerol and raise HDL cholesterol concentrations in healthy middle-aged men. Prostaglandins Leukot Essent Fatty Acids 2008;78:327-35.

80 Dawczynski C, Massey KA, Ness C, et al. Randomized placebocontrolled intervention with n-3 LC-PUFA-supplemented yoghurt: effects on circulating eicosanoids and cardiovascular risk factors. Clin Nutr 2013;32:686-96.

81 Binia A, Vargas-Martínez C, Ancira-Moreno M, et al. Improvement of cardiometabolic markers after fish oil intervention in young Mexican adults and the role of PPAR $\alpha$ L162V and PPAR 2 P12A. J Nutr Biochem 2017;43:98-106.

82 Pishva H, Mehdipour P, Eshraghian MR. Effects of eicosapentaenoic acid supplementation on lipid and lipoprotein profile in hypertriglyceridemic subjects with different proliferator-activated receptor alpha genotypes; 13.

83 Caron-Dorval D, Paquet P, Paradis A-M. Effect of the PPARalpha L162V polymorphism on the cardiovascular disease risk factor in response to $n-3$ polyunsaturated fatty acids. J Nutr Nutr 2008;1:205-12.

84 Itariu BK, Zeyda M, Hochbrugger EE, et al. Long-Chain n-3 PUFAs reduce adipose tissue and systemic inflammation in severely obese nondiabetic patients: a randomized controlled trial. Am J Clin Nutr 2012;96:1137-49.

85 Lindi V, Schwab U, Louheranta A, et al. Impact of the Pro12Ala polymorphism of the PPAR-gamma2 gene on serum triacylglycerol response to n-3 fatty acid supplementation. Mol Genet Metab 2003;79:52-60. 
86 Kotze MJ, Lückhoff HK, Brand T, Pretorius J, et al. Apolipoprotein E $\varepsilon-4$ as a genetic determinant of Alzheimer's disease heterogeneity. Degener Neurol Neuromuscul Dis 2015;5:9.

87 Marais AD. Apolipoprotein E in lipoprotein metabolism, health and cardiovascular disease. Pathology 2019;51:165-76.

88 Kuo C-L, Pilling LC, Atkins JL, et al. ApoE e2 and agingrelated outcomes in 379,000 UK Biobank participants. Aging 2020;12:12222-33

89 Nawawi HM, Chua Y-A, Watts GF. The Brave new world of genetic testing in the management of the dyslipidaemias. Curr Opin Cardiol 2020;35:226-33.

90 Livingston G, Huntley J, Sommerlad A, et al. Dementia prevention, intervention, and care: 2020 report of the Lancet Commission. Lancet 2020;396:413-46.

91 Dorszewska J, Prendecki M, Oczkowska A, et al. Molecular basis of familial and sporadic Alzheimer's disease. Curr Alzheimer Res 2016;13:952-63.

92 ACCE model process for evaluating genetic tests | CDC, 2021. Available: https://www.cdc.gov/genomics/gtesting/acce/index.htm [Accessed 14 Feb 2021].

93 Corella D, Coltell O, Portolés O, et al. A guide to applying the SexGender perspective to nutritional genomics. Nutrients 2018;11:4.

94 Dellinger RW, Garcia AMG, Meyskens FL. Differences in the glucuronidation of resveratrol and pterostilbene: altered enzyme specificity and potential gender differences. Drug Metab Pharmacokinet 2014;29:112-9.

95 Vidaver RM, Lafleur B, Tong C, et al. Women subjects in $\mathrm{NIH}$-funded clinical research literature: lack of progress in both representation and analysis by sex. J Womens Health Gend Based Med 2000;9:495-504.

96 Carvalho-Wells AL, Jackson KG, Lockyer S, et al. Apoe genotype influences triglyceride and C-reactive protein responses to altered dietary fat intake in UK adults. Am J Clin Nutr 2012;96:1447-53.

97 Thifault E, Cormier H, Bouchard-Mercier A, et al. Effects of age, sex, body mass index and APOE genotype on cardiovascular biomarker response to an $n-3$ polyunsaturated fatty acid supplementation. $J$ Nutrigenet Nutrigenomics 2013;6:73-82.
98 Minihane AM, Khan S, Leigh-Firbank EC, Syrah K, Leigh-Firbank Elizabeth C, et al. Apoe polymorphism and fish oil supplementation in subjects with an atherogenic lipoprotein phenotype. Arterioscler Thromb Vasc Biol 2000;20:1990-7.

99 Little J, Higgins JPT, loannidis JPA, et al. STrengthening the REporting of Genetic Association Studies (STREGA)An Extension of the STROBE Statement. PLoS Med 2009;6:e1000022.

100 Strande NT, Riggs ER, Buchanan AH, et al. Evaluating the clinical validity of Gene-Disease associations: an evidence-based framework developed by the clinical genome resource. Am J Hum Genet 2017;100:895-906.

101 Ciesielski TH, Pendergrass SA, White MJ, et al. Diverse convergent evidence in the genetic analysis of complex disease: coordinating omic, informatic, and experimental evidence to better identify and validate risk factors. BioData Min 2014;7:10.

102 Rudkowska I, Paradis A-M, Thifault E, et al. Differences in metabolomic and transcriptomic profiles between responders and non-responders to an n-3 polyunsaturated fatty acids (PUFAs) supplementation. Genes Nutr 2013;8:411-23.

103 Tremblay BL, Cormier H, Rudkowska I, et al. Association between polymorphisms in phospholipase A2 genes and the plasma triglyceride response to an n-3 PUFA supplementation: a clinical trial. Lipids Health Dis 2015;14:12.

104 Ouellette C, Cormier H, Rudkowska I, et al. Polymorphisms in genes involved in the triglyceride synthesis pathway and marine omega-3 polyunsaturated fatty acid supplementation modulate plasma triglyceride levels. J Nutrigenet Nutrigenomics 2013;6:268-80.

105 Keathley J, Garneau V, Marcil V, et al. Clinical practice guidelines using grade and agree II for the impact of genetic variants on plasma Lipid/Lipoprotein/Apolipoprotein responsiveness to omega-3 fatty acids. Front Nutr 2022;8.

106 Ray-Barruel G, Rickard CM. Helping nurses help PIVCs: decision AIDS for daily assessment and maintenance. Br J Nurs 2018;27:S12-18. 